\title{
Propofol suppresses LPS-induced nuclear accumulation of HIF-1 $\alpha$ and tumor aggressiveness in non-small cell lung cancer
}

\author{
NENGLI YANG ${ }^{1,2}$, YAFENG LIANG ${ }^{3}$, PEI YANG ${ }^{2}$ and FUHAI JI ${ }^{1}$ \\ ${ }^{1}$ Department of Anesthesiology, The First Affiliated Hospital of Soochow University, Suzhou, Jiangsu 215006; \\ ${ }^{2}$ Department of Anesthesiology, The First Affiliated Hospital of Wenzhou Medical University, Wenzhou, \\ Zhejiang 325000; ${ }^{3}$ Department of Pediatric Intensive Care Unit, The Second Affiliated Hospital, \\ Wenzhou Medical University, Wenzhou, Zhejiang 325000, P.R. China
}

Received August 2, 2016; Accepted September 9, 2016

DOI: $10.3892 /$ or.2017.5514

\begin{abstract}
Tumor hypoxia has been recognized as a characteristic of the tumor microenvironment and promotes metastasis in a variety of types of cancer. However, in lung cancer, the role of hypoxia-inducible factor $1 \alpha(\mathrm{HIF}-1 \alpha)$ in modulating the cellular response to the inflammation-related microenvironment remains unclear. In the present study, enhanced expression of HIF-1 $\alpha$ accompanied by an increased ROS level was observed in lipopolysaccharide (LPS)-stimulated nonsmall cell lung cancer (NSCLC) cells. In addition, propofol, a general anesthetic, was found to significantly reduce the LPS-induced upregulation of HIF- $1 \alpha$ and ROS in a dosedependent manner. Further study showed that propofol may antagonize the role of LPS in activating HIF-1 $\alpha$ through attenuating the protein stability and nuclear localization of HIF-1 $\alpha$. Moreover, knockdown of HIF-1 $\alpha$ attenuated expression of mesenchymal marker, vimentin, but promoted the expression of epidermal marker, E-cadherin, in the LPS-treated NSCLC cells. Notably, LPS-induced epithelial-to-mesenchymal transition (EMT) was notably suppressed by propofol treatment. Consistently, a wound healing assay revealed that propofol abrogated LPS-stimulated migration of NSCLC cells while overexpression of HIF-1 $\alpha$ reversed the effects of propofol. Similarly, we investigated the influence of propofol on the invasive capability of NSCLC cells. Western blot and RT-PCR analyses indicated that both knockdown of HIF- $1 \alpha$ and treatment of propofol attenuated the LPS-activated expression of MMP2 and MMP9 which are necessary for tumor invasion. However, results from the Transwell assay confirmed that propofol also suppressed cell invasion by decreasing HIF-1 $\alpha$ expression in the LPS-treated NSCLC cells. Analysis of clinical specimens demonstrated abnormal expression of HIF-1 $\alpha$
\end{abstract}

Correspondence to: Dr Fuhai Ji, Department of Anesthesiology, The First Affiliated Hospital of Soochow University, 188 Shizi Street, Suzhou, Jiangsu 215006, P.R. China

E-mail: jifuhai@hotmail.com

Key words: propofol, hypoxia-inducible factor $1 \alpha$, LPS, non-smallcell lung cancer in NSCLC tissues and a poor prognosis in patients with elevated HIF-1 $\alpha$ expression. Thus, the present study suggests a potential strategy for NSCLC by targeting HIF-1 $\alpha$.

\section{Introduction}

The inflammation-associated tumor microenvironment has been demonstrated to promote the aggressiveness of many types of cancers. However, the underlying mechanisms have not been well described. Previous studies have shown a correlation between the inflammatory microenviroment and tumor hypoxia which confers a worse prognosis as well as chemotherapy resistance $(1,2)$. In lung cancer, hypoxia is positively correlated with an increased risk of tumor relapse (3). Lipopolysaccharides (LPS), an integral constituent of the outer cell membrane of gram-negative bacteria, induces systemic inflammation that results in the increase of a variety of inflammatory factors and production of reactive oxygen species (ROS) $(4,5)$. In addition, other studies have reported that LPS displays potent effects on tumor invasion and metastasis (6). In the present study, we investigated the roles of an important hypoxia-activated modulator, hypoxia-inducible factor $1 \alpha$ (HIF-1 $\alpha)$, in LPS-induced hypoxia of non-small cell lung cancer (NSCLC).

HIF-1 is a heterodimer composed of 2 subunits, HIF-1 $\alpha$ and HIF-1 $\beta$. HIF-1 $\beta$ is constitutively expressed while the level of HIF-1 $\alpha$ protein depends on different physiologic conditions (7). Therefore, the HIF-1 $\alpha$ level determines the transcriptional activation and functions of HIF-1 $\alpha$ in response to different oxygen levels. In normoxia, degradation of HIF-1 $\alpha$ by ubiquitination and proteasome leads to suppression of the conformation of the HIF-1 complex. However, under hypoxic conditions, degradation of HIF- $1 \alpha$ is inhibited and nuclear accumulation of HIF- $1 \alpha$ results in the formation of active HIF-1 transcription factors with HIF-1 $\beta$ (8). Abnormal expression or activation of HIF-1 $\alpha$ has been reported in many solid tumors including breast and colorectal cancer, and hepatocarcinoma (9-11). However, the role of HIF-1 $\alpha$ in the tumor progression of lung cancer is still controversial.

Propofol (2,6-diisopropylphenol) is one of the most commonly used intravenous anesthetic agents during surgery. Notably, evidence suggests that propofol possesses antioxidant 
properties and suppresses the inflammatory process both in vitro and in vivo $(12,13)$. However, other studies have shown that propofol has an influence on the proliferation, motility and invasiveness of cancer cells $(14,15)$. More and more studies have indicated a potential antitumor property of propofol. Previous studies have shown that propofol can induce the apoptosis of human leukemia cells and inhibit pulmonary metastasis of osteosarcoma cells $(14,16)$. Consistently, propofol also suppresses the invasion and migration of lung cancer cells (17). Nevertheless, the mechanisms underlying the antitumor effects of propofol are not yet available.

In the present study, we examined the effects of propofol on LPS-induced migration and invasion of NSCLC cells. Moreover, we found that propofol inhibited the aggressive capabilities of NSCLC cells partly through decreasing the expression of HIF-1 $\alpha$ which is induced by inflammatory hypoxia.

\section{Materials and methods}

Cell culture. Human lung adenocarcinoma cell line A549 was purchased from the American Type Culture Collection (ATCC; Manassas, VA, USA) and cultured in RPMI-1640 medium suppplemented with $10 \%$ fetal bovine serum (FBS; Gibco, Carlsbad, CA, USA), $100 \mathrm{mg} / \mathrm{ml}$ streptomycin and $100 \mathrm{IU} / \mathrm{ml}$ penicillin in a $5 \% \mathrm{CO}_{2}$ atmosphere at $37^{\circ} \mathrm{C}$.

Chemicals and reagents. LPS (from Escherichia coli 0111:B4) was purchased from Sigma (St. Louis, MO, USA) and stored in a stock solution of $1 \mathrm{mg} / \mathrm{ml}$. Various concentrations of LPS in the experiments were diluted with serum-free culture medium. Propofol was obtained from Sigma-Aldrich (St. Louis, MO, USA) and diluted in dimethyl sulfoxide (DMSO) for in vitro experiments. Subsequent concentrations of propofol were diluted with culture medium when used. The following antibodies were used in the western blotting or immunohistochemistry (IHC). Antibodies to E-cadherin, vimentin and GAPDH were purchased from Santa Cruz Biotechnology, Inc. (Santa Cruz, CA, USA). Antibodies to MMP2 and MMP9 were purchased from Cell Signaling Technology (CST; Beverly, MA, USA). Antibody to HIF-1 $\alpha$ was purchased from Abcam (Cambridge, UK).

Plasmids and siRNAs. pGL3-HRE plasmids containing 3 repeated hypoxic response elements (HREs) in the promoter region were constructed from pGL3-basic plasmids. HIF-1 $\alpha$ siRNAs were purchased from Santa Cruz Biotechnology, Inc. PcDNA3.1-HIF-1 $\alpha$ and HIF-1 $\alpha$ siRNAs were transfected using Lipofectamine 2000 transfection reagent (Invitrogen, Carlsbad, CA, USA) according to the manufacturer's instructions.

Quantitative real-time PCR. Extraction of total RNA was performed with RNAiso ${ }^{\mathrm{TM}}$ Plus reagent and further reversetranscribed using a PrimeScript ${ }^{\mathrm{TM}}$ RT reagent kit (both from Takara, Tokyo, Japan). SYBR-Green mix (Roche) was used to carry out quantitative PCR according to the manufacturer's instructions. $\beta$-actin served as a loading control.

Western blotting. The whole cell protein was obtained with cold cell lysis buffer and the total protein concentration was measured using the Bradford protein assay (Bio-Rad, Hercules, CA, USA). Equal amount of protein was separated on 8-12\% SDS-PAGE gel and transferred to a nitrocellulose membrane. The membrane was blocked with $5 \%$ milk and then incubated with primary antibodies at $4^{\circ} \mathrm{C}$ overnight. Next, the membranes were incubated with appropriate secondary antibodies at room temperature for $1 \mathrm{~h}$. IRDye ${ }^{\circledR} 800 \mathrm{CW}$ - or IRDye ${ }^{\circledR} 680$-conjugated secondary antibodies were used for staining and then the proteins were detected using an Odyssey ${ }^{\circledR}$ infrared imaging system (both from LI-COR, Lincoln, NE, USA).

Immunofluorescence microscopy. The cells were washed with cold phosphate-buffered saline (PBS) and fixed in 4\% paraformaldehyde. After incubating with primary antibodies, the cells were stained with the fluorescein isothiocyanate (FITC) or tetramethylrhodamine (TRITC)-conjugated secondary antibodies. 4',6-Diamidino-2-phenylindole (DAPI) was used for nuclear staining. At least six randomly chosen fields of view were counted, with each experiment performed in triplicate, and at least 100 total cells were examined in each experiment.

Luciferase reporter assay. A549 cells were plated onto 24-well plates. The next day, the cells were co-transfected with $0.5 \mu \mathrm{g}$ firefly luciferase reporter constructs and $0.01 \mu \mathrm{g}$ pRL-SV40 Renilla luciferase reporter plasmids (Promega, Madison, WI, USA). The pRL-SV40 plasmid was used to normalize the transfection efficiency. Two days after transfection, the cells were lysed and the luciferase activities were measured using a Dual-Luciferase Reporter Assay System (Promega) and a luminometer (LB9507; Berthold, Bad Wildbad, Germany). All experiments were carried out in triplicate.

Wound healing assay. A549 cells were plated at a density of $1 \times 10^{6}$ cells in a $35-\mathrm{mm}$ culture dish and incubated at $37^{\circ} \mathrm{C}$. The next day, a scratch in the form of a lane was made through the confluent monolayers with a sterile white pipette tip. Thereafter, the A549 cells were treated with LPS or propofol. Images of the views for assessment of the cell migration ability at $24 \mathrm{~h}$ after scratch were captured. The wound was evaluated using ImageJ.

Transwell migration assay. A549 cells were seeded on Matrigel-coated membrane inserts with a pore size of $8-\mu \mathrm{m}$ (BD Biosciences, San Diego, CA, USA) in the presence of serum-free medium. The complete medium with or without LPS and propofol was placed in the lower wells of the chamber system. After incubation for $48 \mathrm{~h}$, the undersurface adherent cells that had invaded through the Matrigel were fixed in methanol and stained with $0.5 \%$ crystal violet. The air-dried filter membrane was viewed under a microscope and 4 random fields were selected for cell counting.

Detection of ROS generation. Nicotinamide adenine dinucleotide phosphate oxidase-dependent ROS generation was analyzed by a luminometric assay as previously described (18).

IHC. NSCLC tissue specimens $(\mathrm{n}=187)$ were collected from 2005 to 2010 from the First Affiliated Hospital of Soochow University (Suzhou, China) $(n=127)$ and the First Affiliated Hospital of Wenzhou Medical University (Wenzhou, China) 


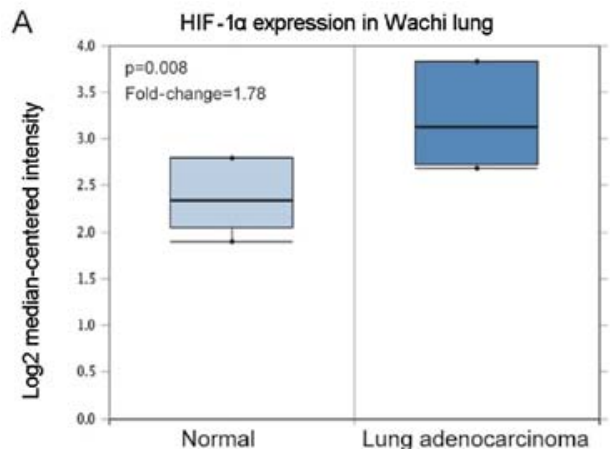

C

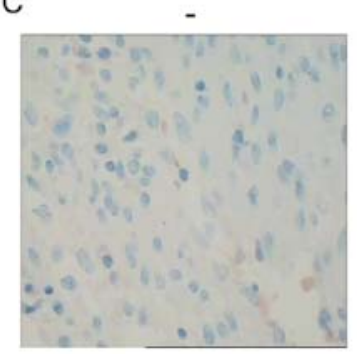

$++$

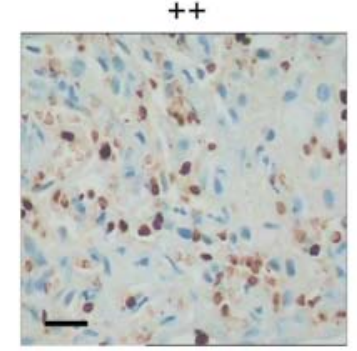



$+++$

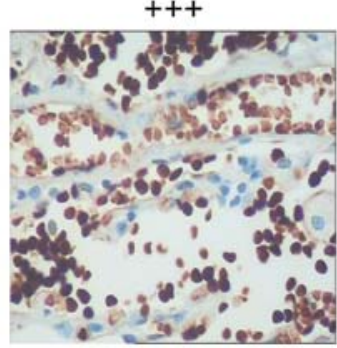

B

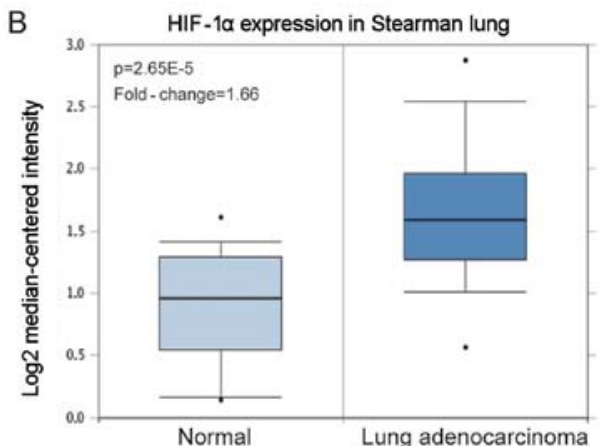

D



Figure 1. Aberrant high expression of hypoxia-inducible factor $1 \alpha(\mathrm{HIF}-1 \alpha)$ in clinical non-small cell lung cancer tissues indicates poor patient prognosis. (A and B) Investigation of lung cancer microarray data sets using Oncomine (www.oncomine.org). (A) Higher HIF-1 $\alpha$ mRNA levels were found in squamous cell lung carcinoma $(n=5)$ when compared with normal lung tissues $(n=5)$ in the Wachi lung data set. (B) Higher HIF-1 $\alpha$ mRNA levels were found in lung adenocarcinoma $(n=20)$ compared with normal lung tissues $(n=19)$ in the Stearman lung data set. (C) The expression level of HIF-1 $\alpha$ protein in clinical specimens of lung cancer was detected using immunohistochemistry with respect to the HIF-1 $\alpha$ expression intensity: negative (-), positive (+), strongly positive (++) and very strongly positive (+++) immunoreactivity (scale bar, $50 \mu \mathrm{m}$ ). (D) The association of HIF-1 $\alpha$ expression with the prognosis of lung cancer patients. Kaplan-Meier overall survival curves indicated that low expression of HIF-1 $\alpha$ in lung cancer tissues was significantly associated with a better overall survival rate. 'Low' or 'high' HIF-1 $\alpha$ level was defined according to its cut-off value, which was defined as the median value of the cohort of patients tested; P<0.05 by log-rank test.

$(n=60)$. Informed consent was obtained from all patients, and the study was approved by the Institutional Review Board of the First Affiliated Hospital of Soochow University and the First Affiliated Hospital of Wenzhou Medical University. All specimens were fixed in $10 \%$ neutral formalin, embedded in paraffin and cut into $4-\mu \mathrm{m}$ sections for immunohistochemical staining. The EnVision ${ }^{\mathrm{TM}}$ two-step method was used (Dako, Hamburg, Germany), as well as the antibody against HIF-1 $\alpha$. To estimate the score for each slide, at least 10 individual fields at x200 were chosen, and 100 cancer cells were counted in each field. The immunostaining intensity was divided into 4 grades: 0 , no expression; 1 , mildly positive; 2 , moderately positive; and 3 , markedly positive. The proportion of positivestaining cells was divided into 5 grades: $0,<10 \% ; 1,11-25 \%$; $2,26-50 \% ; 3,51-75 \%$; and $4,>75 \%$. The staining results were assessed and confirmed by 2 independent investigators blinded to the clinical data. The percentage of positivity of the tumor cells and the staining intensities were then multiplied in order to generate the IHC score, and were graded as 0-3, negative (-); 4-6, positive $(+)$; 7-9, strongly positive $(++)$; and 10-12, very strongly positive $(+++)$. Cases with a discrepancy in scores were discussed to obtain a consensus.

Statistical analysis. The software SPSS 13.0 and GraphPad Prism 5 were used in the statistical analyses. Group distributions were performed with the Student's t-test or one-way analysis of variance. A value of $\mathrm{P}<0.05$ was considered to indicate a statistically significant result.

\section{Results}

Aberrant high expression of HIF-1 $\alpha$ in clinical NSCLC tissues indicates a poor prognosis. To examine the levels of HIF-1 $\alpha$ mRNA in clinical specimens, we investigated lung cancer microarray data sets on Oncomine and found higher HIF-1 $\alpha$ mRNA levels in lung adenocarcinoma when compared with normal lung tissues (Fig. 1A and B). Immunohistochemical staining was carried out to analyze the clinical relevance of HIF-1 $\alpha$ expression in 187 human NSCLC specimens. The expression level of HIF-1 $\alpha$ was increased in the tumor 
Table I. Correlation of the expression of HIF-1 $\alpha$ with clinicopathological features of the NSCLC cases.

\begin{tabular}{|c|c|c|c|c|c|c|}
\hline \multirow[b]{2}{*}{ Characteristics } & \multirow[b]{2}{*}{ Total } & \multicolumn{4}{|c|}{ HIF1 $\alpha$ expression } & \multirow[b]{2}{*}{$\mathrm{P}$-value } \\
\hline & & - & + & ++ & +++ & \\
\hline Total & 187 & 21 & 73 & 67 & 26 & \\
\hline Gender & & & & & & 0.5164 \\
\hline Male & 136 & 15 & 52 & 43 & 16 & \\
\hline Female & 51 & 6 & 21 & 24 & 10 & \\
\hline Age (years) & & & & & & 0.6943 \\
\hline$<57$ & 92 & 13 & 34 & 34 & 11 & \\
\hline$\geq 57$ & 95 & 8 & 39 & 33 & 15 & \\
\hline Tumor size $(\mathrm{cm})$ & & & & & & $0.0452^{\mathrm{a}}$ \\
\hline$\leq 3$ & 86 & 9 & 46 & 24 & 7 & \\
\hline$>3$ & 101 & 12 & 27 & 43 & 19 & \\
\hline Histological type & & & & & & 0.3427 \\
\hline $\begin{array}{l}\text { Squamous cell } \\
\text { carcinoma }\end{array}$ & 75 & 9 & 24 & 27 & 15 & \\
\hline Adenocarcinoma & 112 & 12 & 49 & 40 & 11 & \\
\hline $\begin{array}{l}\text { Lymph node } \\
\text { metastasis }\end{array}$ & & & & & & $0.0049^{b}$ \\
\hline No & 85 & 13 & 41 & 25 & 6 & \\
\hline Yes & 102 & 8 & 32 & 42 & 20 & \\
\hline $\begin{array}{l}\text { Differentiation } \\
\text { status }\end{array}$ & & & & & & $0.0012^{\mathrm{a}}$ \\
\hline Well & 43 & 12 & 23 & 6 & 2 & \\
\hline Moderate & 81 & 6 & 37 & 29 & 9 & \\
\hline Poor & 63 & 3 & 13 & 32 & 15 & \\
\hline TNM stage & & & & & & $0.0003^{\mathrm{a}}$ \\
\hline I/II & 146 & 19 & 66 & 50 & 11 & \\
\hline III/IV & 41 & 2 & 7 & 17 & 15 & \\
\hline
\end{tabular}

HIF- $1 \alpha$, hypoxia-inducible factor $1 \alpha$; NSCLC, non-small cell lung cancer; TNM, tumor-node-metastasis. ${ }^{\mathrm{a}} \mathrm{P}<0.05$.

compared with the normal lung tissues (Fig. 1C). Further analyses showed that the HIF-1 $\alpha$ staining was positively correlated with tumor size, lymph node metastasis, differentiation status and tumor-node-metastasis $(\mathrm{TNM})$ stage $(\mathrm{P}<0.05)$ but not with gender, age and histological type $(\mathrm{P}>0.05)$ (Table I). Moreover, the 5-year overall survival (OS) rate of the HIF-1 $\alpha$ high expression group was significantly lower than that of the HIF-1 $\alpha$ low expression group (18.28 vs. $34.04 \%$; $\mathrm{P}=0.0001$ ) (Fig. 1D). These data suggest that HIF-1 $\alpha$ exhibits aberrant high expression in NSCLC tissues, which is involved in cancer progression and metastasis, and indicative of a poor prognosis.

Expression of HIF-1 $\alpha$ is upregulated by LPS but downregulated by propofol in NSCLC cells. Considering that a close relationship between expression of HIF-1 $\alpha$ and severe inflammation is observed in colorectal carcinoma cells, we aimed to ascertain whether LPS stimulation leads to induction of this transcriptional factor in NSCLC cells. Exposure of A549 cells to different concentrations of LPS caused a dose-dependent accumulation of HIF-1 $\alpha$ at both the mRNA and protein levels, which confirms that LPS-induced pro-inflammation triggers the upregulation of HIF-1 $\alpha$ expression (Fig. 2A-C). As an inflammatory indicator, LPS-induced ROS production in NSCLC cells was also found to be observantly increased along with LPS addition (Fig. 2D). To further examine the effect of propofol on LPS-activated HIF-1 $\alpha$ expression, co-intervention experiments were carried out with increasing concentrations of propofol and HIF- $1 \alpha$ inducer, LPS. The results showed that HIF-1 $\alpha$ expression promoted by LPS in the NSCLC cells was attenuated following treatment with propofol in a dosedependent manner (Fig. 2E-G). Consistently, LPS-induced ROS generation was also abrogated by propofol which suggests its function as an antioxidant agent and inflammatory suppressor (Fig. 2H).

LPS-induced protein stability and nuclear accumulation of $H I F-1 \alpha$ is attenuated by propofol. To understand the regulatory mechanisms of HIF-1 $\alpha$ under inflammatory conditions, we assessed the half-life of the HIF-1 $\alpha$ protein after the indicated treatments. The results showed that the HIF-1 $\alpha$ protein in the LPS-treated group had a much shorter halflife than that noted in the control group, while the half-life of HIF-1 $\alpha$ in the LPS and propofol double-treated group was decreased (Fig. 3A and B). Moreover, translocation of HIF-1 $\alpha$ from the cytoplasm to the nucleus was observed in the NSCLC cells after LPS stimulation. As expected, propofol significantly weakened the effect of LPS on subcellular distribution of HIF-1 $\alpha$ (Fig. 3C and D). Consequently, propofol suppressed the LPS-induced transcriptional activity of HIF-1 $\alpha$ in the NSCLC cells (Fig. 3E). Notably, we found that the expression of EMT-transcription factors (EMT-TFs) were upregulated by LPS, whereas propofol suppressed the upregulation of the EMT-TFs (Fig. 3F). In conclusion, propofol inhibits the expression of HIF-1 $\alpha$-targeting genes which are promoted by LPS via regulating the protein stability and subcellular distribution of HIF-1 $\alpha$ in NSCLC cells.

Propofol impairs LPS-induced migration of NSCLC cells by decreasing HIF- $1 \alpha$ expression. Based on previous studies indicating that LPS induces EMT in cancer cells $(19,20)$, we sequentially analyzed the expression of two EMT markers, E-cadherin and vimentin in the NSCLC cells after LPS stimulation. Our findings revealed that the expression of E-cadherin was significantly downregulated in the LPS-treated group compared to that noted in the control, while vimentin expression was substantially increased (Fig. 4A and B). To further confirm the effects of propofol on LPS-induced EMT, LPS-stimulated NSCLC cells were co-treated with propofol and the expression of EMT markers was measured. As expected, propofol reversed LPS-induced EMT, causing re-induction of E-cadherin and suppression of vimentin expression (Fig. 4A and B). Considering that propofol reduces the expression of HIF-1 $\alpha$ induced by LPS, knockdown of HIF-1 $\alpha$ by siRNAs in NSCLC cells was performed under LPS stimulation. The results showed that, similar to propofol, knockdown of HIF-1 $\alpha$ significantly blocked EMT activated by LPS (Fig. 4C and D). Consistently, in a wound healing assay, propofol weakened the LPS-induced 
A

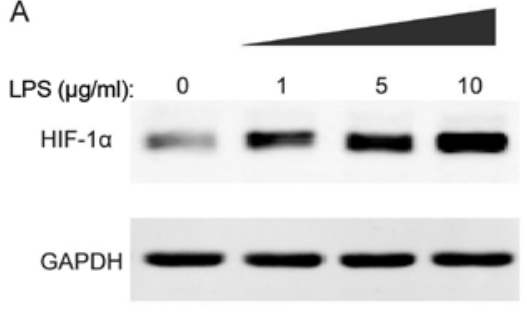

C

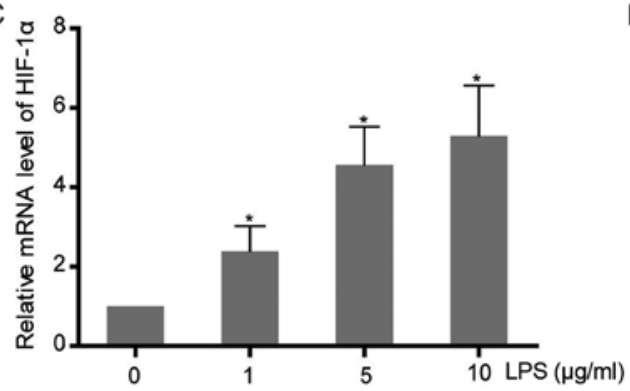

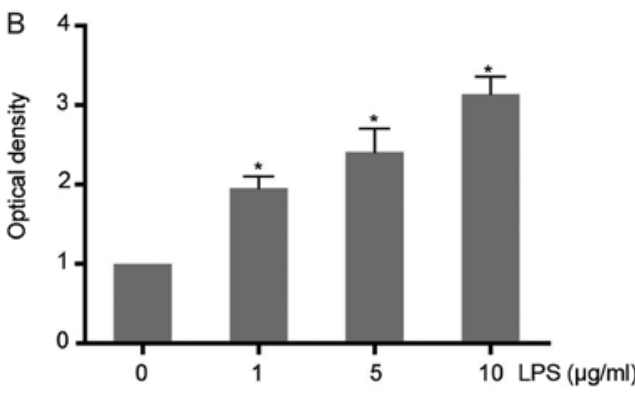

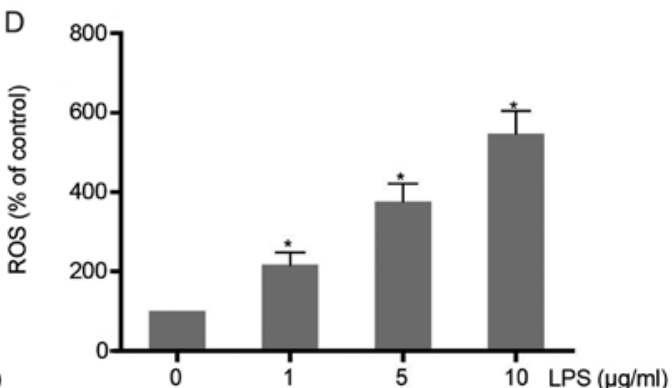

E



G
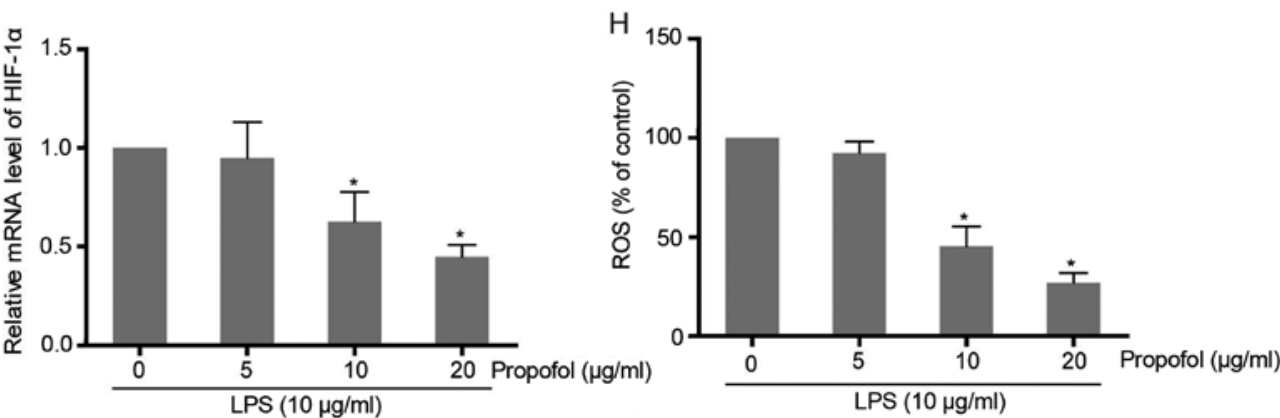

Figure 2. Expression of hypoxia-inducible factor $1 \alpha$ (HIF-1 $\alpha$ ) is upregulated by lipopolysacharide (LPS) but downregulated by propofol in NSCLC cells. (A) A549 cells were exposed to different concentrations of LPS for $12 \mathrm{~h}$. The expression levels of HIF-1 $\alpha$ protein were then analyzed by western blotting. GAPDH served as a control. (B) Quantitative data of western blotting in A; ${ }^{*} \mathrm{P}<0.05$. (C) Following treatment as described in A, the levels of HIF-1 $\alpha$ mRNA were analyzed by qRT-PCR. The mRNA levels of the indicated genes were normalized to actin; ${ }^{*} \mathrm{P}<0.05$. (D) Following treatment as described in A, generation of ROS was measured as outlined in Materials and methods; ${ }^{*} \mathrm{P}<0.05$. (E) A549 cells were co-treated with $10 \mu \mathrm{g} / \mathrm{ml} \mathrm{LPS}$ and different concentrations of propofol for $12 \mathrm{~h}$. The expression levels of HIF-1 $\alpha$ protein were then analyzed by western blotting. GAPDH served as a control. (F) Quantitative data of the western blotting in E; ${ }^{*} \mathrm{P}<0.05$. (G) Following treatment as described in E, the levels of HIF-1 $\alpha$ mRNA were analyzed by qRT-PCR. The mRNA levels of the indicated genes were normalized to actin; ${ }^{*} \mathrm{P}<0.05$. (H) Following treatment as described in E, generation of ROS was measured as outlined in Materials and methods; ${ }^{*} \mathrm{P}<0.05$.

capability of migration in the NSCLC cells (Fig. 4E and F). Notably, overexpression of HIF-1 $\alpha$ counteracted the inhibitory effect of propofol on LPS-activated migration in the NSCLC cells (Fig. 4E and F), which demonstrated that propofol suppressed the LPS-promoted migration of NSCLC cells by decreasing HIF-1 $\alpha$ expression.

Propofol suppresses LPS-induced invasion of NSCLC cells by diminishing HIF-1 $\alpha$ expression. Although several studies have found that LPS could enhance cell invasive capacity in human cancer cells (21), the underlying mechanisms have not been well illustrated. In the present study, MMP2 and MMP9, two genes related to invasion, were observed to be increased in the NSCLC cells treated with LPS at both the mRNA and protein levels (Fig. 5A and B). However, the promotive influence of LPS on expression of MMP2 and MMP9 were largely reversed by co-incubation with propofol in NSCLC cells (Fig. 5A and B). Further studies indicated that abrogation of HIF-1 $\alpha$ by siRNAs also attenuated the expression of MMP2 and MMP9 activated by LPS treatment in the NSCLC cells (Fig. 5C and D), which 
A

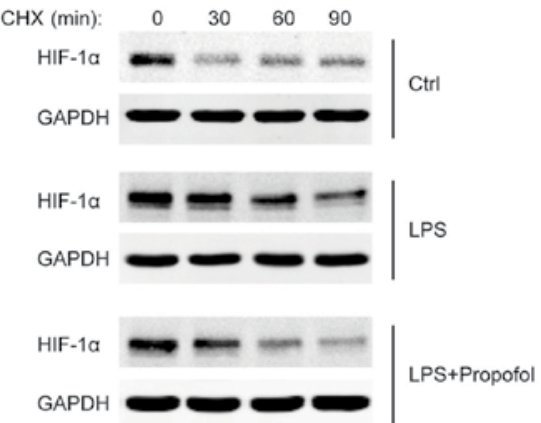

B

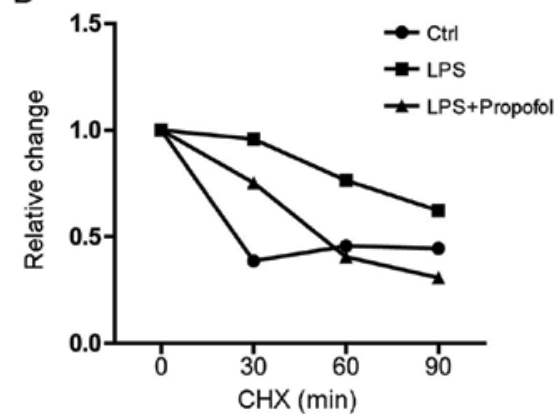

$C_{\text {LPS }}$
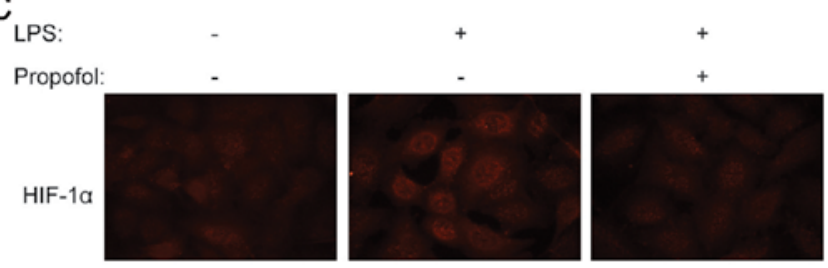

D

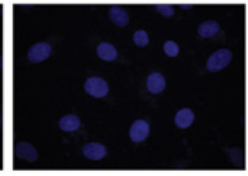

DAPI


F



Figure 3. Lipopolysaccharide (LPS)-induced protein stability and nuclear accumulation of hypoxia-inducible factor $1 \alpha$ (HIF-1 $\alpha$ ) is attenuated by propofol. (A) A549 cells were pretreated with $10 \mu \mathrm{g} / \mathrm{ml} \mathrm{LPS} \mathrm{or} 20 \mu \mathrm{g} / \mathrm{ml}$ propofol for $12 \mathrm{~h}$ and then treated with $10 \mu \mathrm{g} / \mathrm{ml}$ cycloheximide (CHX) for the indicated times. Whole-cell lysates were harvested and analyzed by western blot analyses. (B) Densitometric analysis of data from (A) using ImageJ to determine the stability of HIF-1 $\alpha$. (C) Immunofluorescent staining for HIF-1 $\alpha$ in A549 cells exposed to the indicated reagents for $12 \mathrm{~h}$ (scale bar, $20 \mu \mathrm{m}$ ). (D) The pattern of nucleocytoplasmic distribution of HIF-1 $\alpha$ in $\mathrm{C}$ was quantified. The number of cells was determined and is presented as the percentage of the total population. A minimum of 100 cells was counted for each experiment and data are presented as means \pm SD from 3 independent experiments; ${ }^{*} \mathrm{P}<0.05$, compared with the control or LPS + propofol group. (E) A549 cells were transfected with a pGL3-HRE plasmid which contains 3 repeated HREs. The transcriptional activity of HIF-1 $\alpha$ was measured after treating the A549 cells with the indicated reagents; ${ }^{*} \mathrm{P}<0.05$. (F) Relative mRNA levels of EMT-TFs and VEGF in A549 cells treated with the indicated reagents. The mRNA levels of the indicated genes were normalized to actin; ${ }^{\mathrm{P}}<0.05$. EMT-TFs, epithelial-to-mesenchymal transition-transcription factors.

suggests that HIF- $1 \alpha$ may play a role as a pivotal target of propofol for inhibiting invasion-related genes. Moreover, the interplay of LPS and propofol on the invasion of NSCLC cells in vitro was evaluated by Transwell assays. The results showed that the acquired ability of invasion in the NSCLC cells stimulated by LPS was partly eliminated by treatment with propofol (Fig. 5E and F). Notably, overexpression of HIF-1 $\alpha$ rescued LPS-induced cell invasion which was suppressed by propofol (Fig. 5E and F). Therefore, it is reasonable to hypothesize that propofol suppressed LPS-activated cell invasion by decreasing HIF-1 $\alpha$ expression in the LPS-treated NSCLC cells.

\section{Discussion}

Hypoxia-inducible factor $1 \alpha$ (HIF-1 $\alpha)$ activation has been demonstrated in cancer progression. Abnormal expression 


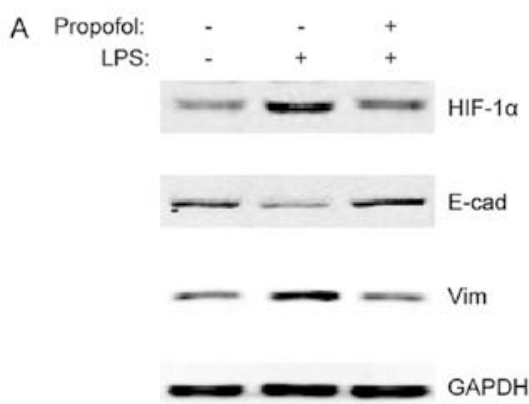

B



C siHIF-1a: $\quad+$

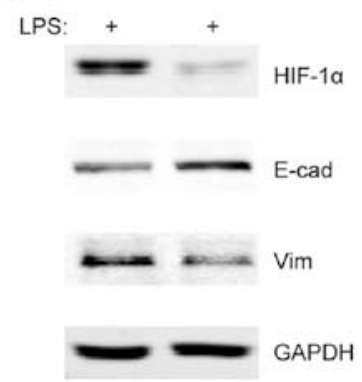

E LPS: Propofol:
HIF-1a:



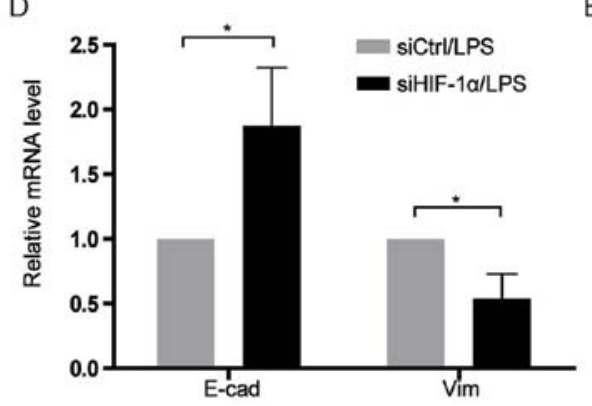

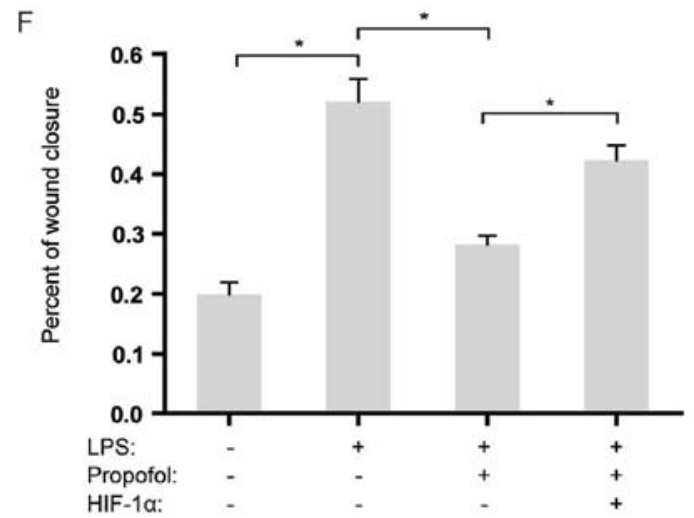

Figure 4. Propofol impairs lipopolysacharide (LPS)-induced migration of NSCLC cells by decreasing hypoxia-inducible factor $1 \alpha$ (HIF-1 $\alpha$ ) expression. (A) The expression profiles of HIF-1 $\alpha$, E-cadherin and vimentin in A549 cells were examined by western blotting after treatment with $10 \mu \mathrm{g} / \mathrm{ml} \mathrm{LPS} \mathrm{or} 20 \mu \mathrm{g} / \mathrm{ml}$ propofol for $12 \mathrm{~h}$. GAPDH served as a control. (B) Following treatment as described inA, the mRNA levels of E-cadherin and vimentin were analyzed by qRT-PCR. The mRNA levels of the indicated genes were normalized to actin; "P<0.05. (C) A549 cells were transfected with siRNAs targeting HIF-1 $\alpha$ and then treated with LPS for $12 \mathrm{~h}$. The expression levels of HIF-1 $\alpha$, E-cadherin, and vimentin were detected using western blotting. GAPDH served as a control. (D) Following treatment as described in C, the mRNA levels of E-cadherin and vimentin were analyzed by qRT-PCR. The mRNA levels of the indicated genes were normalized to actin; ${ }^{\mathrm{P}} \mathrm{P}<0.05$. (E) A549 cells were transfected with HIF-1 $\alpha$-overexpression plasmids or treated with the indicated reagents. Cell migration was examined by wound healing assay (scale bar, $200 \mu \mathrm{m}$ ). (F) Percentage of wound closure $48 \mathrm{~h}$ after wound scratch in $\mathrm{E}$; ${ }^{*} \mathrm{P}<0.05$.

of HIF-1 $\alpha$ has been found in a variety of human cancers and is associated with tumor growth, metastasis and poor prognosis $(8,22)$. As a hypoxia-dependent transcription factor, HIF-1 $\alpha$ regulates the expression of numerous genes involved in angiogenesis, metabolism and proliferation $(23,24)$. Insufficient blood supply or inflammation can be one of the reasons for the hypoxic environment during cancer development. Therefore, HIF-1 $\alpha$ is an important microenvironment regulator in tumor progression (25). In the present study, clinical analysis indicated a significant upregulation of HIF-1 $\alpha$ at both the mRNA and protein levels in lung cancer specimens compared with levels noted in the normal tissues. Further investigation of overall survival suggested that patients with high HIF-1 $\alpha$ expression had a relatively poor prognosis, which confirmed the tumor-promoting role of HIF-1 $\alpha$ in lung cancer.
More recent evidence suggests that inflammatory stimuli accompanied by hypoxia can activate HIF- $1 \alpha$ during the history of malignant tumors (26). Thus, to explore the potential mechanisms underlying the elevated expression of HIF- $1 \alpha$ in lung cancer, LPS was used to induce an inflammatory response in NSCLC cells. Our findings indicated that LPS treatment notably increased HIF-1 $\alpha$ expression as well as the level of ROS in the NSCLC cells. Notably, hypoxia has been shown in previous studies to produce ROS which contributes to stabilizing and activating HIF1 (27). However, the mRNA level of HIF- $1 \alpha$ is also induced by LPS, which implies a complicated regulatory process for HIF-1 $\alpha$ in response to LPS. To further study the relationship between LPS-induced inflammation and HIF-1 $\alpha$ expression, propofol, an anti-inflammatory agent, was applied to inhibit the cellular response to LPS. As expected, 

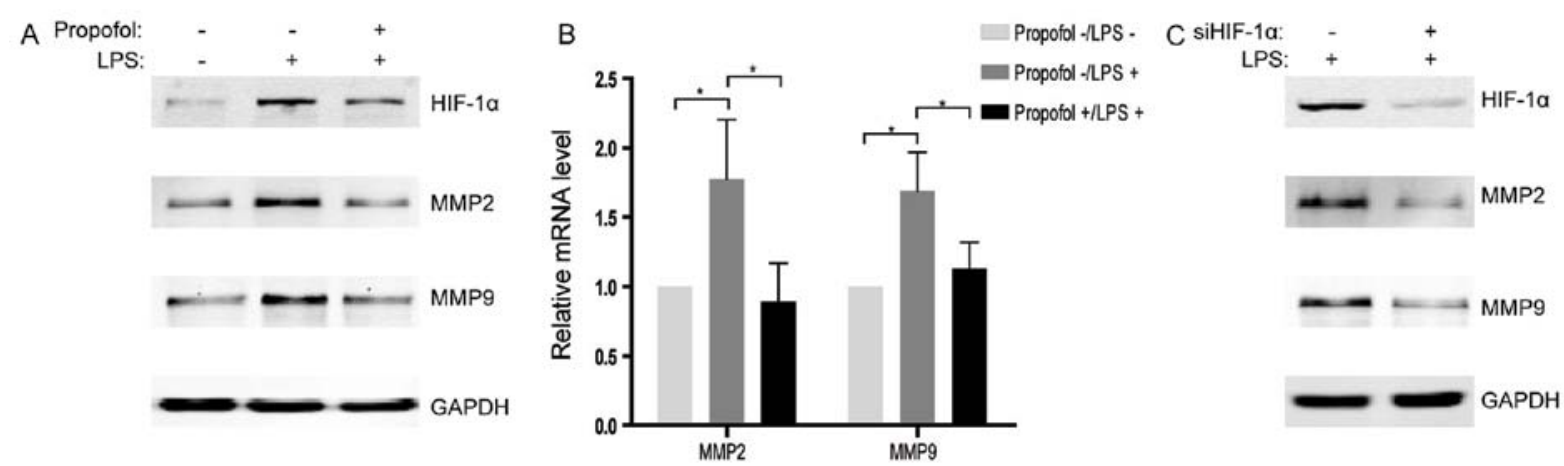

D

\section{E}


Figure 5. Propofol suppresses lipopolysacharide (LPS)-induced invasion of NSCLC cells by diminishing hypoxia-inducible factor $1 \alpha$ (HIF-1 $\alpha$ ) expression. (A) The protein levels of HIF-1 $\alpha$, MMP2 and MMP9 in A549 cells were assessed using western blotting after treatment with $10 \mu \mathrm{g} / \mathrm{ml} \mathrm{LPS}$ or $20 \mu \mathrm{g} / \mathrm{ml}$ propofol for $12 \mathrm{~h}$. GAPDH served as a control. (B) Following treatment as described in A, the mRNA levels of MMP2 and MMP9 were analyzed by qRT-PCR The mRNA levels of the indicated genes were normalized to actin; " $P<0.05$. (C) A549 cells were transfected with siRNAs targeting HIF-1 $\alpha$ and then treated with LPS for $12 \mathrm{~h}$. The expression levels of HIF-1 $\alpha$, MMP2 and MMP9 were detected using western blotting. GAPDH served as a control. (D) Following treatment as described in C, the mRNA levels of MMP2 and MMP9 were analyzed by qRT-PCR. The mRNA levels of the indicated genes were normalized to actin; ${ }^{*} \mathrm{P}<0.05$. (E) A549 cells were transfected with HIF-1 $\alpha$ overexpression plasmids or treated with the indicated reagents. Cell invasion was examined using Matrigel-coated Transwell assay (scale bar, $200 \mu \mathrm{m}$ ). (F) Numbers of invasive cells in E were quantified; ${ }^{*} \mathrm{P}<0.05$.

propofol suppressed the upregulation of HIF-1 $\alpha$ caused by LPS stimulation in the NSCLC cells. Simultaneously, ROS production generated after LPS addition was also decreased by propofol. Although propofol has been verified to possess antioxidant property $(28,29)$, whether propofol inhibits HIF-1 $\alpha$ expression by eliminating ROS needs to be further investigated.

In addition to transcriptional regulation, the functions of HIF-1 $\alpha$ depend on its protein stability and subcellular localization. Under a hypoxic condition, ubiquitination of HIF-1 $\alpha$ is suppressed and increased HIF-1 $\alpha$ binds to HIF-1 $\beta$ to form the HIF-1 transcription complex (30). HIF1 then translocates to the nucleus, where it binds to the hypoxic response element (HRE) within the promoters of its target genes $(31,32)$. In the present study, LPS was found to enhance the stability of HIF-1 $\alpha$ as well as its nuclear localization. Meanwhile, propofol impaired the effects of LPS on HIF-1 $\alpha$ regulation. With regard to the promotive effect of ROS on activating HIF-1 $\alpha$, our findings suggested that propofol may disrupt the functions of HIF-1 $\alpha$ via antagonizing LPS-induced ROS.

As an anesthetic, propofol is widely used in relieving the pain of patients with chronic cancer as an adjuvant therapy. In addition, our findings suggest that propofol suppresses LPS-activated migration and invasion of NSCLC cells. Momentously, overexpression of HIF-1 $\alpha$ restored the capacities of migration and invasion suppressed by propofol in NSCLC cells, which indicates that HIF-1 $\alpha$ is a pivotal regulator involved in the antitumor characteristics of propofol. Notably, in breast cancer, propofol was found to reduce MMP expression by inhibiting NF- $\kappa \mathrm{B}$ activity (33). Other evidence revealed that phosphorylated ERK $1 / 2$ is markedly reduced 
after propofol treatment, which leads to apoptosis in lung cancer (34). Therefore, the effects of propofol on different cancer types involve various signaling pathways and biological processes.

In conclusion, our findings demonstrated that LPSstimulated inflammation enhanced the functions of HIF-1 $\alpha$ by increasing the mRNA levels, protein stability and nuclear localization of HIF-1 $\alpha$ in NSCLC cells, which led to concomitant increases in markers and mediators of migration and invasion. Meanwhile, propofol treatment suppressed all of those effects and appeared to do so by suppressing HIF-1 $\alpha$. As such, the present study establishes a new mechanistic explanation for the effects of propofol on lung cancer. However, in consideration of the aberrant HIF-1 $\alpha$ expression in lung cancer tissues, the present study provides further evidence for the application of propofol in treating patients with lung cancer.

\section{References}

1. Giatromanolaki A, Koukourakis MI, Sivridis E, Pastorek J, Wykoff CC, Gatter KC and Harris AL: Expression of hypoxiainducible carbonic anhydrase-9 relates to angiogenic pathways and independently to poor outcome in non-small cell lung cancer. Cancer Res 61: 7992-7998, 2001

2. Giatromanolaki A, Koukourakis MI, Sivridis E, Turley H, Talks K, Pezzella F, Gatter KC and Harris AL: Relation of hypoxia inducible factor 1 alpha and 2 alpha in operable non-small cell lung cancer to angiogenic/molecular profile of tumours and survival. Br J Cancer 85: 881-890, 2001.

3. Le QT, Chen E, Salim A, Cao H, Kong CS, Whyte R, Donington J, Cannon W, Wakelee H, Tibshirani R, et al: An evaluation of tumor oxygenation and gene expression in patients with early stage non-small cell lung cancers. Clin Cancer Res 12: 1507-1514, 2006.

4. Beutler B: Inferences, questions and possibilities in Toll-like receptor signalling. Nature 430: 257-263, 2004.

5. Pchejetski D, Nunes J, Coughlan K, Lall H, Pitson SM, Waxman J and Sumbayev VV: The involvement of sphingosine kinase 1 in LPS-induced Toll-like receptor 4-mediated accumulation of HIF-1 $\alpha$ protein, activation of ASK1 and production of the pro-inflammatory cytokine IL-6. Immunol Cell Biol 89 $268-274,2011$

6. Liu WT, Jing YY, Yan F, Han ZP, Lai FB, Zeng JX, Yu GF, Fan QM, Li R, Zhao QD, et al: LPS-induced CXCR4-dependent migratory properties and a mesenchymal-like phenotype of colorectal cancer cells. Cell Adh Migr 0: 1-11, 2016.

7. Wang GL, Jiang BH, Rue EA and Semenza GL: Hypoxia-inducible factor 1 is a basic-helix-loop-helix-PAS heterodimer regulated by cellular $\mathrm{O}_{2}$ tension. Proc Natl Acad Sci USA 92: 5510-5514, 1995.

8. Rankin EB and Giaccia AJ: Hypoxic control of metastasis. Science 352: 175-180, 2016

9. Wang T, Gilkes DM, Takano N, Xiang L, Luo W, Bishop CJ, Chaturvedi P, Green JJ and Semenza GL: Hypoxia-inducible factors and RAB22A mediate formation of microvesicles that stimulate breast cancer invasion and metastasis. Proc Natl Acad Sci USA 111: E3234-E3242, 2014.

10. Nagaraju GP, Bramhachari PV, Raghu G and El-Rayes BF: Hypoxia inducible factor- $1 \alpha$ : Its role in colorectal carcinogenesis and metastasis. Cancer Lett 366: 11-18, 2015.

11. Tian H, Huang P, Zhao Z, Tang W and Xia J: HIF-1 $\alpha$ plays a role in the chemotactic migration of hepatocarcinoma cells through the modulation of CXCL6 expression. Cell Physiol Biochem 34: 1536-1546, 2014.

12. Chen J, Gu Y, Shao Z, Luo J and Tan Z: Propofol protects against hydrogen peroxide-induced oxidative stress and cell dysfunction in human umbilical vein endothelial cells. Mol Cell Biochem 339: 43-54, 2010.

13. Kobayashi K, Yoshino F, Takahashi SS, Todoki K, Maehata Y, Komatsu T, Yoshida K and Lee MC: Direct assessments of the antioxidant effects of propofol medium chain triglyceride/long chain triglyceride on the brain of stroke-prone spontaneously hypertensive rats using electron spin resonance spectroscopy. Anesthesiology 109: 426-435, 2008.
14. Mammoto T, Mukai M, Mammoto A, Yamanaka Y, Hayashi Y, Mashimo T, Kishi Y and Nakamura H: Intravenous anesthetic, propofol inhibits invasion of cancer cells. Cancer Lett 184: $165-170,2002$

15. Altenburg JD, Harvey KA, McCray S, Xu Z and Siddiqui RA: A novel 2,6-diisopropylphenyl-docosahexaenoamide conjugate induces apoptosis in T cell acute lymphoblastic leukemia cell lines. Biochem Biophys Res Commun 411: 427-432, 2011.

16. Tsuchiya M, Asada A, Arita K, Utsumi T, Yoshida T, Sato EF, Utsumi $\mathrm{K}$ and Inoue M: Induction and mechanism of apoptotic cell death by propofol in HL-60 cells. Acta Anaesthesiol Scand 46: 1068-1074, 2002.

17. Wu KC, Yang ST, Hsia TC, Yang JS, Chiou SM, Lu CC, Wu RS and Chung JG: Suppression of cell invasion and migration by propofol are involved in down-regulating matrix metalloproteinase-2 and p38 MAPK signaling in A549 human lung adenocarcinoma epithelial cells. Anticancer Res 32: 4833-4842, 2012.

18. Kapiszewska M, Cierniak A, Elas M and Lankoff A: Lifespan of etoposide-treated human neutrophils is affected by antioxidant ability of quercetin. Toxicol In Vitro 21: 1020-1030, 2007.

19. Chen MC, Chang WW, Kuan YD, Lin ST, Hsu HC and Lee CH: Resveratrol inhibits LPS-induced epithelial-mesenchymal transition in mouse melanoma model. Innate Immun 18: 685-693, 2012.

20. Huang T, Chen Z and Fang L: Curcumin inhibits LPS-induced EMT through downregulation of NF- $\kappa B-S n a i l$ signaling in breast cancer cells. Oncol Rep 29: 117-124, 2013.

21. Yang H, Wang B, Wang T, Xu L, He C, Wen H, Yan J, Su H and Zhu X: Toll-like receptor 4 prompts human breast cancer cells invasiveness via lipopolysaccharide stimulation and is overexpressed in patients with lymph node metastasis. PLoS One 9: e109980, 2014.

22. Chen S, Zhang M, Xing L, Wang Y, Xiao Y and Wu Y: HIF-1 $\alpha$ contributes to proliferation and invasiveness of neuroblastoma cells via SHH signaling. PLoS One 10: e0121115, 2015.

23. Wilde BR and Ayer DE: Interactions between Myc and MondoA transcription factors in metabolism and tumourigenesis. Br J Cancer 113: 1529-1533, 2015.

24. Wan J, Che Y, Kang N and Wu W: SOCS3 blocks HIF-1 $\alpha$ expression to inhibit proliferation and angiogenesis of human small cell lung cancer by downregulating activation of Akt, but not STAT3. Mol Med Rep 12: 83-92, 2015.

25. Ward C, Langdon SP, Mullen P, Harris AL, Harrison DJ, Supuran CT and Kunkler IH: New strategies for targeting the hypoxic tumour microenvironment in breast cancer. Cancer Treat Rev 39: 171-179, 2013.

26. Bredholt G, Mannelqvist M, Stefansson IM, Birkeland E, B $\varnothing \mathrm{TH}$ Øyan AM, Trovik J, Kalland KH, Jonassen I, Salvesen HB, et al: Tumor necrosis is an important hallmark of aggressive endometrial cancer and associates with hypoxia, angiogenesis and inflammation responses. Oncotarget 6: 39676-39691, 2015.

27. Gatenby RA and Gillies RJ: Why do cancers have high aerobic glycolysis? Nat Rev Cancer 4: 891-899, 2004.

28. Adaramoye OA, Akinwonmi O and Akanni O: Effects of propofol, a sedative-hypnotic drug, on the lipid profile, antioxidant indices, and cardiovascular marker enzymes in wistar rats. ISRN Pharmacol 2013: 230261, 2013.

29. Braz MG, Braz LG, Freire CM, Lucio LM, Braz JR, Tang G, Salvadori DM and Yeum KJ: Isoflurane and propofol contribute to increasing the antioxidant status of patients during minor elective surgery: A randomized clinical study. Medicine 94: e1266, 2015.

30. Cockman ME, Masson N, Mole DR, Jaakkola P, Chang GW, Clifford SC, Maher ER, Pugh CW, Ratcliffe PJ and Maxwell PH: Hypoxia inducible factor-alpha binding and ubiquitylation by the von Hippel-Lindau tumor suppressor protein. J Biol Chem 275: 25733-25741, 2000.

31. Semenza GL, Agani F, Booth G, Forsythe J, Iyer N, Jiang BH, Leung S, Roe R, Wiener $\mathrm{C}$ and $\mathrm{Yu} A$ : Structural and functional analysis of hypoxia-inducible factor 1. Kidney Int 51: 553-555, 1997.

32. Chachami G, Paraskeva E, Mingot JM, Braliou GG, Görlich D and Simos G: Transport of hypoxia-inducible factor HIF-1alpha into the nucleus involves importins 4 and 7. Biochem Biophys Res Commun 390: 235-240, 2009.

33. Li Q, Zhang L, Han Y, Jiang Z and Wang Q: Propofol reduces MMPs expression by inhibiting NF- $\kappa \mathrm{B}$ activity in human MDA-MB-231 cells. Biomed Pharmacother 66: 52-56, 2012.

34. Song J, Shen Y, Zhang J and Lian Q: Mini profile of potential anticancer properties of propofol. PLoS One 9: e114440, 2014. 